\title{
Effects of Restraining Steel Exports from the Republic of Korea and Other Countries to the United States and the European Economic Community
}

\author{
David G. Tarr
}

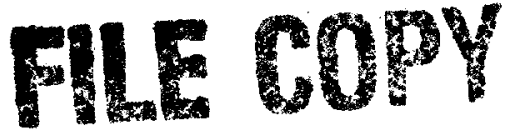

\begin{abstract}
In this article a model is developed to evaluate the impact on an exporting country of a restraint imposed on its export by an importing economy in the context of a three-region model of world trade in a single product. The welfare changes in any of the three regions in the model and in the global economy can be evaluated.

The model is applied to the restraints imposed on steel exports from the Republic of Korea to the United States and the European Economic Community (EEC). The United States and the EEC are found to have incurred significant losses as a result of the restraints. The largest part of these losses are quota rents transferred to Korea and the rest of the world. Under reasonable parameter assumptions, Korea and the rest of the world obtain net gains from the quotas, because the resource misallocation costs are smaller than the quota rents.

The model is modified to analyze a tariff barrier rather than a quantitative restraint. It is found that an "equivalent" tariff on steel transforms Korea and the rest of the world from net gainers to net losers as a result of a restraint.
\end{abstract}

The steel producers of the United States and the European Economic Community have undergone significant dislocations as steel demand has declined since 1975, and the location of the lowest steelmaking costs has shifted first to Japan in the 1960 s and early 1970s, and later to the Republic of Korea and Brazil. ${ }^{1}$ The U.S. and EEC governments have responded with increasing protection. Since 1978, the EEC has maintained an extensive system of "voluntary restraint agreements" (VRAs), which limit steel imports. Although the United States had a period of

1. See Tarr (forthcoming) for the details of the decline in demand, output, and employment, as well as the shifts in relative costs.

David G. Tarr is a senior economist with the U.S. Federal Trade Commission. This article is based on a larger study by the author (Tarr 1986a) which was completed while the author was a long-term consultant in the Development Research Department of the World Bank. The author would like to acknowledge the helpful comments of J. Michael Finger, Vittorio Corbo, Brian Hindley, Gregory Ingram, Morris Morkre, Hans Mueller, Chong Nam, Theophilos Priovolos, and Billy Yoo.

Copyright (C) 1987 by the International Bank for Reconstruction and Development / THE WORLD BANK. 
roughly free trade in steel products from 1982-84 (with the exception of the restraints on imports from the EEC), it imposed quotas in late 1984 on virtually all significant suppliers of steel to the United States.

The costs to the United States of its newly adopted system of quotas have been examined elsewhere (Tarr and Morkre 1984); in this article the costs to Korea and other countries which export steel to the United States and EEC are examined.

Based on the methodology of Corden (1957), many authors have estimated the costs to an importing nation of a restraint it imposes on a particular product. Empirical efforts to determine the costs to an exporting nation of a restraint imposed on its exports of a particular, somewhat disaggregated, product by an importing nation are much less common. Development of a methodology to estimate such costs has also received relatively little attention. ${ }^{2}$ In section I, a brief description of the model and the welfare methodology is provided. The model is specified in mathematical terms in the appendix; more detail is provided in Tarr (1986a). The structure of the vRAs is discussed in section II. In section III, results of the simulations of the model using the best parameter estimates are presented, and alternative elasticity and policy simulations are examined.

\section{Summary of the Model}

The country on which we focus specific attention is Korea, which has emerged as a low-cost supplier of steel. Although estimates of the welfare effects of a trade restriction are normally made for a single country in a partial equilibrium context, too many important interaction effects may be left out of a model that examined Korea alone. Most notably, the amount of the quota rents that the exporting nation obtains from a VRA is crucial to estimating the welfare effects. It is clearly necessary to include the restraining importing nation in the model to estimate the quota rents effectively. It is important also to include other suppliers of steel.

Thus, a three-region model of world steel trade has been developed with Korea $(K)$ as one of the regions. Since both the United States and the EEC restrain steel imports, they are treated as one region, denoted $U$. The rest of the world constitutes the remaining region, $R$ : exports from this region are also restrained by agreements with the United States and EEC.

The means by which export quotas are imposed facilitates the transfer of rents to exporting countries. Restraint of exports, together with competition by importers, allows rent capture by exporters. If there is monopolistic importing, the outcome is less clear. As there are many steel importers, however, the most reasonable assumption regarding the steel quotas is that importers do not capture the rent.

It is reasonable to treat steel from different regions as differentiated products (the "Armington [1969] assumption"). ${ }^{3}$ This means that each region has three

2. Magee (1972) provides a starting point for the analysis.

3. For a justification of this and other empirical assumptions, as well as a full derivation of the model, see Tarr (1986a). 
demand functions for steel (one for each region's steel products) and each demand function depends on prices from each of the regions. This gives a total of twenty-seven own and cross-elasticities of demand in the model. There are also three supply elasticities, one for each region. A methodology has been developed (Tarr 1986b) for choosing between two competing sets of estimates of the elasticities of demand: the Armington elasticities and those available from Grossman (1982). Employing this methodology, a set of demand elasticity estimates has been obtained for the United States and EEc based on the Grossman estimates, while the Armington elasticities have been utilized for the other two regions of the model.

The estimating procedure involves first assuming that the prices and quantities observed in 1984 are equilibrium values determined by the specified system of supply and demand equations. This allows calibration of the constants of the equations. Next, the quotas are imposed and the model is modified accordingly. With the system of supply and demand functions modified by the quotas, new predicted prices and quantities are determined. Changes between predicted prices and quantities and the actual prices and quantities of 1984 are attributed to the effects of the quota.

A methodology has been developed for calculating the welfare effects of the quotas on all three regions and the world. The change in welfare for any region is defined to be the change in producers' plus consumers' surplus. The technique for performing the welfare calculation, which is an extension of the Burns (1973) methodology, is developed in Tarr (1986a).

Figure 1 depicts the relevant costs of restraints on Korean exports in its home market. $D_{0}$ is the prequota demand curve for Korean steel from all sources, and $D_{1}$ is the postquota demand. $C\left(Q_{K}\right)$ is the Korean supply curve for steel, taken to be the horizontal sum of the individual firms' marginal cost curves. This assumes that Korean and rest-of-world suppliers equate price to marginal costs and that the marginal costs of suppliers are increasing-there are no relevant unrealized economies of scale. Korean home market prequota equilibrium is at price $P_{K}^{O}$ and quantity $Q_{K}^{0}$, and the equilibrium shifts to $P_{K}^{1}$ and $Q_{K}^{1}$ after the imposition of the quota. In the figure, $Q_{i j}^{O}$ is the quantity of steel the region $i$ purchases from the region $j$ in the prequota equilibrium, for $i$ and $j$ elements of the set $W=\{K, U, R\} ; Q_{i j}^{l}$ is defined analogously for the postquota equilibrium. For example, $Q_{U K}^{1}$ is the quantity of steel the region $U$ purchases from Korea $(K)$ after the imposition of the quota.

Since the quota on Korean exports results in a decline in demand for Korean steel, the postquota price and quantity of steel supplied in Korea declines. With less Korean steel production, Korean resources must be shifted into their next best alternative use. The loss to the Korean economy caused by this shift of resources to less productive alternatives is measured by the triangle of deadweight loss, $L_{1}$. The lower price of steel in Korea induces greater consumption of home steel in Korea; at prequota prices the opportunity value of the steel to Korean consumers at the margin was $P_{K}^{0}$. The triangle $L_{2}$ measures the deadweight consumption loss, 
Figure 1. Welfare Costs of Restraints on Korean Steel Exports: Home Market Costs

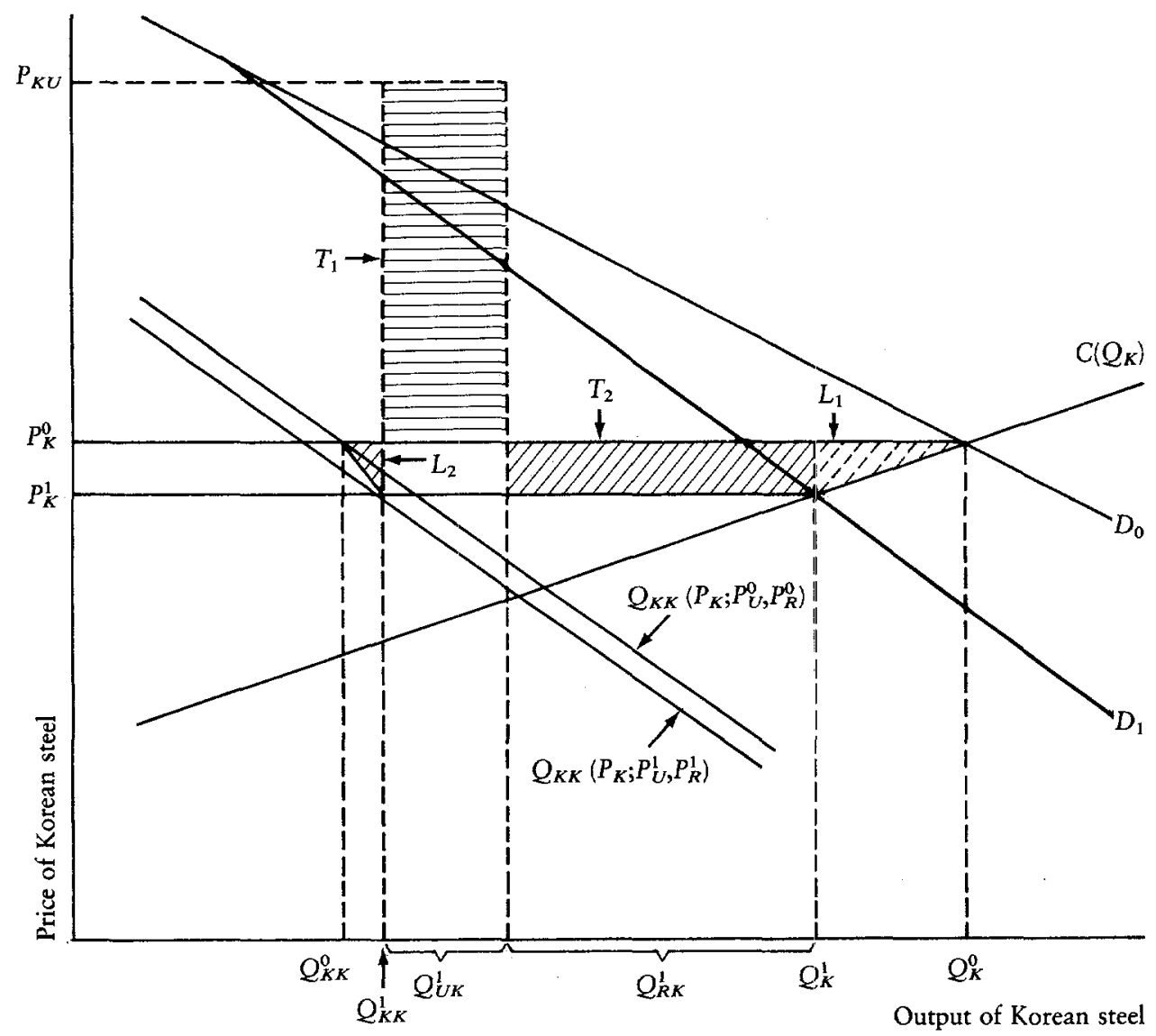

Key: Regions $-K=$ Korea; $R=$ rest of the world; $U=$ United States and EEC. Welfare $-L=$ deadweight loss; $T=$ rent transfer.

this area being the excess of export earnings above the value to consumers of the increased consumption.

Figure 1 also displays two areas of rent transfers. As a result of the quotas, Korea obtains a higher price $\left(P_{K U}\right)$ on its sales in the region $U$. These rents are depicted by the rectangle $T_{1}$. Since Korean steel sells at a lower price to $R$ (rest of the world) after the quotas $\left(P_{K}^{1}\right.$ instead of $\left.P_{K}^{0}\right)$, Korea loses inframarginal rents on these sales. This loss of rents is depicted by the rectangle $T_{2}$.

In figure 2, the Korean demand curves for steel from the region $R$ are depicted: because of the differentiation of the product, two-way trade occurs between Korea and the rest of the world. Since the price of steel from $R$ declines after the quotas are imposed in $U$-the rest of the world is also restrained by quotasKorean consumers gain surplus on the purchases of steel from $R$. A direct application of the Burns methodology implies that the Korean gain in consumers' 
Figure 2. Changes in Korean Consumer Surplus on Purchases of Steel from the Rest of the World

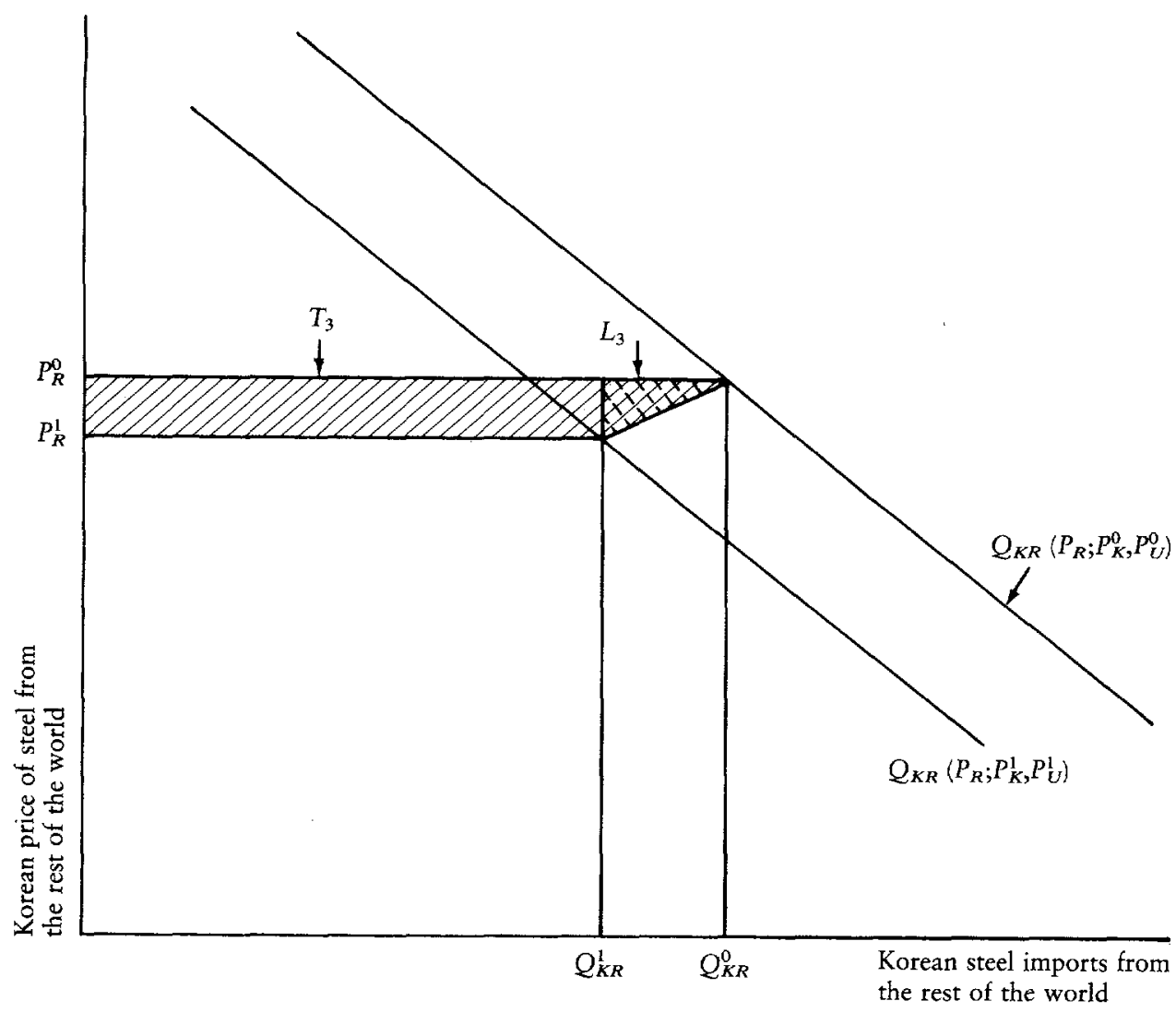

Key: Regions $-K=$ Korea; $R=$ rest of the world; $U=$ United States and EEC. Welfare $-L=$ deadweight loss; $T=$ rent transfer.

surplus on its purchases of steel from $R$ is the rectangle $T_{3}$ plus the triangle $L_{3}$. A third figure analogous to figure 2 could also be drawn, depicting the changes in welfare attributable to the changes in Korean purchases of steel from the region $U$. The welfare effects are also analogous.

Thus for Korea, the change in welfare can be reduced to the sum of eight terms. There is an area $\left(L_{1}\right)$ of production inefficiency and an area $\left(L_{2}\right)$ representing consumption inefficiency for Korea of its domestically produced steel. Korea gains rents on its sales to the region $U\left(T_{1}\right)$; these are the "quota rents." Korea also experiences rent losses on its sales to the rest of the world $\left\langle T_{2}\right\rangle$. Since the price of steel from $U$ increases, Korea loses consumers' surplus on its purchases from $U$ (these terms are not depicted); Korea gains surplus on its purchases from $R$ $\left(T_{3}+L_{3}\right)$. For $R$, there are eight terms with a fully analogous interpretation to those for Korea that must be calculated to assess the welfare effects. The region 
$U$ loses quota rents on its purchases from Korea and from $R$ and suffers deadweight consumption losses on these purchases. It gains rents, however, on sales to $R$ and $K$.

The sum of the change in the three regions' welfare is the change in world welfare. Since one region's rent gain is another's loss, rent transfers do not change world welfare unless different countries are accorded different welfare weights or real resources are expended in securing these rent transfers. The analysis has not incorporated the effects of such rent seeking. As discussed below, the change in world welfare can be decomposed into the sum of the deadweight loss triangles.

\section{Allocation of Quota Rights}

As rents are an essential aspect of the analysis, it is desirable to consider the allocation of the quota rights before discussing the results of the model. The voluntary restraint agreements that the United States and the EEC maintain are bilateral agreements with the major exporters to their home markets. The U.S. agreements with Japan and Korea are typical of the U.S. agreements with non-EEC countries.

In the case of Korea, the VRA is an "arrangement" between the governments of the United States and Korea. It stipulates that Korea will issue export licenses and certificates for the relevant products and that the United States will require presentation of such certificates as a condition of import into the United States. Korea is given specific quantity allowances, on roughly an annual basis, of particular products with quarterly adjustments based on demand forecasts for the U.S. market.

The arrangement stipulates that the Korean Ministry of Trade and Industry (MTI) is responsible for administering the export certificate scheme. The U.S. Department of Commerce provides quarterly reports to MTI regarding the ceiling amount of the specified exports. MTI determines the share of the total allowed exports that goes to each of the Korean steel companies reportedly based on 1983-84 benchmark export performance. MTI has delegated the administrative responsibility for issuing certificates and monitoring adherence to the arrangement to steel industry associations in Korea. ${ }^{4}$

The arrangement between the governments of the United States and Japan is very similar to that between the United States and Korea. While the responsible agency is not specified in the VRA, the Japanese Ministry of International Trade and Industry (MITI) determines company shares calculated from the U.S. Department of Commerce quarterly ceiling data, based on the export performance of the companies during the 1981-84 period. The administrative functions are also handled by an industry organization, the Japan Iron and Steel Exporters Association-U.S.A., explicitly formed for this purpose.

4. The Korean Pipe and Tube Association issues certificates for pipe and tube products, and the Korean Iron and Steel Association issues the certificates for other steel products. 
Table 1. Change in Steel Prices

(1984 U.S. dollars per metric ton)

\begin{tabular}{lr} 
Korea & -2.38 \\
United States and EEC & 0.38 \\
Rest of the world & -0.20 \\
Korean steel in United States and EEC & 24.34 \\
Steel from rest of the world in United States and EEC & 19.37 \\
\hline
\end{tabular}

Note: Calculated as postquota equilibrium price minus price in prequota equilibrium. Source: Author's calculations based on data sources detailed in Tarr (1986a).

\section{Summary of Results for the Best-Parameter Estimates}

Empirical results of the model, based on the best estimates of the parameters, are discussed below. The discussion starts with the initial price impact, goes on to outline the effects on trade flows, and culminates with an explanation of the overall welfare costs resulting from changes in rents, and production and consumption inefficiency.

\section{The Effect on Prices}

Table 1 shows that, as a result of the imposition of the quotas, the price of Korean steel in the United States and EEC rises by $\$ 24.34$ per metric ton. Similarly, the price of steel from the rest of the world in $U$ rises by $\$ 19.37$ per metric ton. These amounts measure the quota rents per ton earned by Korea and the rest of the world on their remaining sales to the United States and EEC. Conversely, the prices of steel from Korea and the rest of the world decline outside the United States and EEC by $\$ 2.38$ and $\$ 0.20$, respectively. ${ }^{5}$

\section{The Pattern of Production}

The prices of steel from Korea and the rest of the world decline outside the United States and EEC because imposition of the quotas decreases the demand for steel from these regions. Sales of Korean steel are estimated to decline by 107 thousand metric tons and those of the rest of the world by 3,079 thousand metric tons (table 2). The total decline in sales from Korea and the rest of the world is less than the reduction in their sales to the United States and EEC because both regions increase their sales in their home markets. Exports from Korea to the United States and EEC decline because of the quota, but increase to the rest of the world. The increase in Korean exports to the rest of the world and decrease in exports from the rest of the world to Korea are explained by the decline in price of Korean steel relative to steel from the rest of the world.

The second column of table 2 indicates that the United States and EEC sell more steel after the quota. The increase in total sales of United States and EEC steel, however, is less than the increase in its home market sales because the United States and EEC export less steel: sales are diverted from exports to home markets.

5. The greater decline in the price of Korean steel relative to the drop in price of steel from the rest of the world is attributable to the greater supply elasticity of steel from the rest of the world. 
Table 2. Change in Steel Trade Using Best Estimates of Parameters (thousands of metric tons)

\begin{tabular}{lccrr}
\hline \multicolumn{1}{c}{ Sales } & \multicolumn{4}{c}{ Sales } \\
\cline { 2 - 5 } & From Korea & $\begin{array}{c}\text { From United States } \\
\text { and EEC }\end{array}$ & $\begin{array}{c}\text { From rest of } \\
\text { the world }\end{array}$ & Total \\
\hline To Korea & 113 & -2 & -19 & 92 \\
To United States and EEC & -312 & 1,218 & $-3,261$ & $-2,355$ \\
To rest of the world & 92 & -51 & 201 & 242 \\
Total & -107 & 1,165 & $-3,079$ & $-2,021$ \\
\hline
\end{tabular}

Note: Calculated as postquota minus prequota equilibrium.

Source: Author's calculations based on data sources detailed in Tarr (1986a).

The percentage change in output is estimated to be relatively small for all regions: $-0.79 \%$ for Korea; $-0.98 \%$ for the rest of the world; and $0.72 \%$ for the United States and EEC.

\section{The Pattern of Consumption}

The United States and EEC consume less steel due to the increase in the price of steel from all regions in the United States and EEC, but consume more home-produced steel (table 2). Korea and the rest of the world consume more steel after the imposition of the quota because the drop in their demand for steel from the United States and EEC is more than offset by their increased consumption of steel from $K$ and $R$ due to the decrease in their prices. The world consumes about 2 million tons less steel after the quota.

\section{Welfare Effects-Korea}

The welfare effects for all three regions are presented in table 3 . Korea is estimated to gain about $\$ 32.4$ million as a result of the quota. The table shows that the effect of the rent transfers dominates the production and consumption inefficiency losses. The quota-induced higher prices that Korea receives on its sales in the United States and EEC result in an increase of $\$ 41.9$ million in quota rents. The combined effect of the production and consumption deadweight losses is about one-quarter of a million dollars. Korea lowers its domestic price and its price in the rest of the world, however, which results in a loss of $\$ 9.8$ million in inframarginal rents on its sales to the rest of the world. Korea gains $\$ 0.4$ million in total changes in consumers' surplus. The gain in consumers' surplus on its purchases from the rest of the world (where the price has fallen) exceeds the decline in consumers' surplus on its purchases from the United States and EEC (where the price has risen). Since Korea purchases much more steel from the rest of the world than it does from the United States and EEC, this result is not surprising. Moreover, since Korean consumers gain surplus on their purchases of domestic steel (due to its price decrease), we can conclude that overall, Korean consumers' surplus increases.

These results may not be surprising to some, though a model which incorporates unrealized economies of scale might be expected to change the results significantly. 
Table 3. Welfare Costs of U.S. and EEC Steel Import Quotas: Best Estimates of Parameters

(thousands of 1984 U.S. dollars per year)

\begin{tabular}{lcccc}
\hline & Korea & $\begin{array}{c}\text { United States } \\
\text { and EEC }\end{array}$ & $\begin{array}{c}\text { Rest of } \\
\text { the world }\end{array}$ & World \\
\hline Total & 32,388 & $-471,216$ & 402,757 & $-36,071$ \\
Sources of total & & & & \\
Change in rents from sales to & - & 69 & -548 \\
$\quad$ Korea & 41,937 & - & 400,614 \\
$\quad$ United States and EEC & $-9,767$ & 6,638 & - \\
$\quad$ Rest of the world & & & \\
Inefficiency costs & -128 & - & -309 \\
$\quad$ Production & -135 & $-35,372$ & -20 \\
$\quad$ Consumption & 481 & $-442,551^{\mathrm{a}}$ & 3,020 & \\
Change in consumers' surplus on imports & & &
\end{tabular}

- Not applicable.

Note: Calculated as welfare in postquota equilibrium minus welfare in prequota equilibrium. Negative numbers indicate a decline in welfare.

a. The consumption inefficiency costs of U.S. and EEC consumers on purchases of non-home-produced steel are recorded in the line immediately above and are excluded here to avoid double counting.

Source: Author's calculations based on data sources detailed in Tarr (1986a).

The observed high capacity utilization in the Korean steel industry, however, argues for modeling the industry with a lack of unrealized economies of scale.

\section{Welfare Effects-Rest of the World}

The rest of the world is estimated (table 3 ) to gain $\$ 402.8$ million as a result of the imposition of the quotas. Again the quota rents it earns on sales to the United States and EEC ( $\$ 400.6$ million) dominate the results. The production and consumption inefficiency or deadweight losses are relatively insignificant $(\$ 0.329$ million). Compared with the inframarginal rent losses of Korea, the rest of the world loses relatively little in inframarginal rents on sales to Korea because its price outside of the United States and EEC falls by less. For the same reason, the rest of the world gains relatively more on consumers' surplus changes outside its home market than does Korea.

\section{Welfare Effects-United States and EEC}

The biggest losses as a result of the imposition of the quotas are borne by the United States and EEC, with an estimated $\$ 471$ million in net welfare costs. While the United States and EEC gain about $\$ 6.7$ million in inframarginal rents on sales to Korea and the rest of the world, this is offset by the loss of consumers' surplus of $\$ 478$ million on its purchases of steel from Korea and the rest of the world. In the case of the United States and EEC, these consumers' surplus losses are decomposed in table 3 into consumption inefficiencies of $\$ 35.4$ million and rent transfers to $K$ and $R$ of $\$ 442.6$ million. Over 90 percent of the loss of consumers in the United States and EEC is captured by producers in Korea and the rest of the world, as reflected in the gains in rents for $K$ and $R$ in table 3. 
The $\$ 35.4$ million difference between the losses of consumers in the United States and EEC and the gains in rents of Korea and the rest of the world is the substantial deadweight losses of consumers in the United States and EEC. That is, consumers in the United States and EEC who were at the margin, but were purchasing steel from Korea or the rest of the world, are squeezed out of the market for steel from these regions and purchase products that were less desirable to them at the prequota prices. Consumers in the United States and EEC lose \$31.6 million and $\$ 3.8$ million resulting from reduced imports from the rest of the world and Korea, respectively (figures are not shown in table 3 ).

There is also a significant transfer of income from consumers to producers in the United States and EEc. In addition to rents obtained from exports to Korea and the rest of the world (the $\$ 6.7$ million total from table 3), producers also capture $\$ 62$ million in the loss of consumers' surplus on domestic purchases of United States and EEC steel. Thus, the total loss to consumers in the United States and EEC is $\$ 533$ million per year, not just the $\$ 471$ million shown in table 3; but producers there gain the difference.

What do the United States and EEC obtain and give up as a result of the VRAs? On the one hand, they obtain a small increase in production in the home region and an increase in profits for home producers. On the other hand, the vRAs also result in a large transfer of income toward the exporting regions. As a result of these large transfers, the United States and EEC lose significantly more than they do under the "equivalent tariff," where their losses are confined to the inefficiency costs of protection. These transfers, however, clearly reduce the opposition of the exporting regions, which thereby receive some compensation. Indeed, the estimates suggest they are overcompensated for the inefficiency losses imposed on them through the protection.

\section{Welfare Effects-the World}

It is estimated that the world loses $\$ 36.1$ million per year as a result of the imposition of the system of United States-EEC quotas. This is simply equal to the sum of the change in welfare for the three regions. Further insight can be obtained, however, by decomposing the change in world welfare into appropriate deadweight loss triangles. The great bulk of these losses ( $\$ 35.4$ million) derives from deadweight losses of consumers in the United States and EEC on their purchases of steel from Korea ( $\$ 3.8$ million) and the rest of the world ( $\$ 31.6$ million). Table 3 refers to production and consumption inefficiencies in $K$ and $R$, which (for $K$ ) correspond to the areas $L_{1}$ and $L_{2}$ in figure 1 . It can be shown, however (Tarr 1986a), that the sum of Korean aggregate production inefficiency plus its consumption inefficiency is equal to its production inefficiency on its sales to $R$ and $U$. Moreover, it is shown that Korea's production inefficiency on its sales to $R$ is captured by consumers in $R$ as additional surplus. Thus, from the perspective of the world, the only inefficiency costs borne by Korea are the production inefficiencies attributable to its lost sales in $U$. An analogous result holds for $R$. Production inefficiencies borne by producers in $K$ and $R$ on lost sales 
in $U$ are $\$ 0.372$ million and $\$ 0.327$ million, respectively. Thus, the losses to the world can be reduced to production and consumption inefficiencies related to imports into $U$. This is consistent with the Harberger (1971) principle that since price equals marginal costs in all other markets, there are no resource misallocation costs related to reallocations in those markets. The deadweight losses estimates are unchanged if the equivalent tariff method of protection is adopted.

\section{Summary of Best Estimates}

Welfare gains for Korea and the rest of the world result from the large quota rents earned on sales to the United States and EEC. The resource misallocation costs incurred by Korea and the rest of the world are small in relation to the rent transfers, so that the net effect of the VRAs on the exporting nations is beneficial. Since one region's positive rent transfer is another region's negative rent transfer, the rent transfers do not affect world welfare unless they induce economically wasteful behavior. Thus, there is a decline in world welfare equal to the sum of the resource misallocation costs for all the regions.

The protecting economies, however, suffer a significant decline in welfare. They lose the resource misallocation costs plus the rent transfers to the nations from which they import. Their producers gain from the restraints, but most of these gains are offset by additional losses to their consumers, above the losses to the economy shown in table 3 .

The experience of the Organization of Petroleum-Exporting Countries cartel should help to make these results intuitive. In the mid-1970s, by effectively organizing most of the world's oil exporters to the non-centrally planned economies, the cartel dramatically increased its welfare through rent transfers. It does not make any difference in the global welfare analysis whether the restraint on the exports is imposed by the exporting region or the importing region. What matters is the level of the restraint and how significant are the suppliers who are not restrained. (In the next section simulations are performed that demonstrate the importance of restraining alternative suppliers in this model.) In the case of steel exports, the United States and the EEC have restrained exports from virtually all significant suppliers. This allows exporters to capture monopoly rents arising from the restriction of supply since other suppliers cannot compete and drive down those rents.

\section{Limitations of the Model}

The model can be extended in a number of ways:

Rent seeking. There are many ways that rent seeking (broadly defined) might dissipate the rents of the exporting nations. For example, lobbying activities, allocation of quota rights to other than the most efficient suppliers, and transshipment activities would serve to reduce the rents. To the extent that rent seeking is important empirically, these estimates (which ignore the rent-seeking effects) overstate the benefits to the exporting nations from the quotas. 
Economies of scale. If there are unrealized economies of scale in Korea or the rest of the world, these would be expected to increase the inefficiency costs associated with the output reduction caused by the quotas.

Cartelization. Where import competition would otherwise prohibit cartelization, producers in the restraining region may be able to collude behind the protection of vRAs. Any such cartelization, which would raise prices above marginal costs in the restraining region, would add further to the costs of protection in the restraining region.

New entry. The effects of the restraints on entry have not been analyzed. Potential steel producers may be discouraged from entering because of fear of restraint in the major export markets. Conversely, the existence of quota rents for and restraints on the most efficient suppliers may encourage new entry. By diverting demand, new entry would lower the rents of the incumbent suppliers in the restrained region.

Second-best considerations. The model has assumed that private and social costs and benefits are identical in the alternate use of resources.

Elasticity assumptions. The impact of alternate elasticities and policies on the estimates has not yet been considered. This is addressed in the next section.

\section{Alternate Elasticity and Policy Simulations of the Model}

\section{Different Quota Levels}

The alternate policies of a more restrictive quota on Korea and a less restrictive quota on the rest of the world have also been simulated in the model. The results of these simulations are combined in tables 4,5 , and 6 . The results of the simulation of a less restrictive quota on $R$ (just one ton less than its prequota equilibrium) are shown without parentheses. The results of a tighter export quota on Korea (reducing exports by 413,000 tons rather than the prior 312,000 ) are shown in parentheses. It was found that Korean welfare decreased with a loosening of the restraint on $R$, and the welfare of $R$ increased with a tightening of the restraint on Korea. That is, the welfare of one of the restrained regions increases or decreases, as the restraint on the other region is tightened or loosened, respectively. In addition, there was a very small decrease in the welfare

Table 4. Simulated Change in Steel Prices: Higher Quotas for Rest of World and Lower Quotas for Korea (in Parentheses)

(1984 U.S. dollars per metric ton per year)

\begin{tabular}{lrr} 
Korea & -2.35 & $(-3.14)$ \\
United States and EEC & 0.03 & $(0.39)$ \\
Rest of the world & 0.00 & $(-0.20)$ \\
Korean steel in United States and EEC & 11.12 & $(27.94)$ \\
Steel from rest of the world in United States and EEC & 1.27 & $(19.77)$ \\
\hline
\end{tabular}

Note: Calculated as price in postquota equilibrium minus price in prequota equilibrium.

Source: As in table 1. 
Table 5. Simulated Change in Steel Trade: Higher Quotas for Rest of the World and Lower Quotas for Korea (in Parentheses) (thousands of metric tons per year)

\begin{tabular}{lrrrrrr}
\hline & \multicolumn{5}{c}{ Sales } \\
\cline { 2 - 6 } \multicolumn{1}{c}{ Sales } & From Korea & $\begin{array}{c}\text { From United States } \\
\text { and EEC }\end{array}$ & \multicolumn{2}{c}{$\begin{array}{c}\text { From rest of } \\
\text { the world }\end{array}$} & \multicolumn{1}{c}{ Total } \\
\hline To Korea & $113(150)$ & -2 & $(-2)$ & -22 & $(-27)$ & 89 \\
To United States and EEC & $-312(-413)$ & $83(1,245)$ & $-1(-3,261)$ & $-230(-2,429)$ \\
To rest of the world & $93(122)$ & $-5(-52)$ & -29 & $(192)$ & 60 & $(262)$ \\
Total & $-106(-141)$ & $77(1,190)$ & $-52(-3,096)$ & $-81(-2,047)$ \\
\hline
\end{tabular}

Note: Calculated as postquota minus prequota equilibrium.

Source: As in table 1.

of Korea with the tighter restraint on it, implying that the tighter restraint exceeded the optimal level of monopoly restriction of export. In the case of a significantly less binding restraint on $R$, the costs to the United States and EEC are reduced dramatically (by over 90 percent), and the gains to Korea and $R$ decrease.

Table 6. Simulated Welfare Costs of U.S. and EEC Steel Import Quotas: Higher Quotas for Rest of the World and Lower Quotas for Korea (in Parentheses) (thousands of 1984 U.S. dollars per year)

\begin{tabular}{|c|c|c|c|c|}
\hline & Korea & $\begin{array}{l}\text { United States } \\
\text { and EEC }\end{array}$ & $\begin{array}{l}\text { Rest of } \\
\text { the world }\end{array}$ & World \\
\hline Total & $\begin{array}{r}9,270 \\
(32,359)\end{array}$ & $\begin{array}{r}-50,877 \\
(-485,563)\end{array}$ & $\begin{array}{r}39,504 \\
(414,214)\end{array}$ & $\begin{array}{r}-2,103 \\
(-38,990)\end{array}$ \\
\hline \multicolumn{5}{|l|}{$\begin{array}{l}\text { Sources of total } \\
\text { Change in rents from sales to }\end{array}$} \\
\hline Korea & - & $\begin{array}{r}5 \\
(71)\end{array}$ & $\begin{array}{r}-9 \\
(-550)\end{array}$ & \\
\hline United States and EEC & $\begin{array}{c}19,163 \\
(45,316)\end{array}$ & - & $\begin{array}{r}30,420 \\
(409,084)\end{array}$ & \\
\hline Rest of the world & $\begin{array}{r}-9,640 \\
(-12,982)\end{array}$ & $\begin{array}{r}437 \\
(6,779\rangle\end{array}$ & - & \\
\hline \multicolumn{5}{|l|}{ Inefficiency costs } \\
\hline Production & $\begin{array}{l}-124 \\
(-222)\end{array}$ & - & $\begin{array}{r}0^{a} \\
(-312)\end{array}$ & \\
\hline Consumption & $\begin{array}{l}-133 \\
(-235)\end{array}$ & $\begin{array}{c}-1,736 \\
(-38,012)\end{array}$ & $\begin{array}{r}0^{\mathrm{a}} \\
(-19)\end{array}$ & \\
\hline Change in consumers' surplus on imports & $\begin{array}{r}5 \\
(482)\end{array}$ & $\begin{array}{r}-49,583^{b} \\
(-454,400)\end{array}$ & $\begin{array}{c}9,093 \\
(6,011)\end{array}$ & \\
\hline
\end{tabular}

- Not applicable.

Note: Calculated as welfare in postquota equilibrium minus welfare in prequota equilibrium. Negative numbers indicate a decline in welfare.

a. The small amount of production and consumption inefficiency for the rest of the world is rounded off to zero.

b. The consumption inefficiency costs of U.S. and EEC consumers on purchases of non-home-produced steel is recorded in the line immediately above and is excluded here to avoid double counting.

Source: As in table 1. 
Table 7. Simulated Change in Steel Prices: Alternative Demand Elasticities (1984 U.S. dollars per metric ton)

\begin{tabular}{lr} 
Korea & -2.38 \\
United States and EEC & 0.34 \\
Rest of the world & 0.20 \\
Korean steel in United States and EEC & 5.23 \\
Steel from rest of the world in United States and EEC & 17.19 \\
\hline
\end{tabular}

Note: Calculated as price in postquota equilibrium minus price in prequota equilibrium. The U.S. own elasticity for Korean steel is taken to be -10 , and the U.S. cross-elasticity of demand for Korean steel with respect to the price of steel from the rest of the world is taken to be 0.5 .

Source: As in table 1.

Table 8. Simulated Change in Steel Trade: Alternative Demand Elasticities (thousands of metric tons)

\begin{tabular}{lccrr}
\hline & \multicolumn{4}{c}{ Sales } \\
\cline { 2 - 5 } \multicolumn{1}{c}{ Sales } & From Korea & $\begin{array}{c}\text { From United States } \\
\text { and EEC }\end{array}$ & $\begin{array}{c}\text { From rest of } \\
\text { the world }\end{array}$ & Total \\
\hline To Korea & 113 & -2 & -19 & 92 \\
To United States and EEC & -312 & 1,077 & -3261 & -2496 \\
To rest of the world & 92 & -46 & 198 & 244 \\
Total & -107 & 1,029 & -3082 & $-2,160$ \\
\hline
\end{tabular}

Note: Calculated as postquota equilibrium minus prequota equilibrium. The U.S. own elasticity for Korean steel is taken to be -10 , and the U.S. cross-elasticity of demand for Korean steel with respect to the price of steel from the rest of the world is taken to be 0.5 .

Source: As in table 1.

\section{Alternate Elasticity Assumptions}

Some alternative elasticity assumptions have also been simulated in the model. Most notably, we attempted to determine if there were elasticity values that would result in a loss in Korean welfare as a result of the existing system of quotas; the results of that simulation are presented in tables 7,8 , and 9 . The selected elasticities in this simulation are: -10 for the United States and EEC elasticity of demand for Korean steel with respect to a change in the price of Korean steel in the United States and EEC (instead of the prior -4.512); and 0.5 for the United States and EEC elasticity of demand for Korean steel with respect to a change in the price of steel from $R$ in the United States and EEC (instead of the prior 4.503). While the selected elasticities are theoretically plausible, they are not values for which we have empirical support. In these cases, however, the net decline in Korean welfare is due to lost inframarginal rents on its sales to $R$, rather than because the resource misallocation costs come to dominate.

In addition, simulations have been performed that estimated the effects of increased substitutability of steel products in the dernand functions of the regions. It was found that the less differentiated the products among regions, the less the costs to the world, the United States, and the EEC, and the smaller the gains to Korea and $R$ of the existing quota system. ${ }^{6}$ This is essentially

6. See Tarr (1986a) for the detailed estimates of this simulation. 
Table 9. Simulated Welfare Costs of U.S. and EEC Steel Import Quotas:

Alternative Demand Elasticities

(thousands of 1984 U.S. dollars per year)

\begin{tabular}{lrrrr}
\hline & Korea & $\begin{array}{c}\text { United States } \\
\text { and EEC }\end{array}$ & $\begin{array}{c}\text { Rest of } \\
\text { the world }\end{array}$ & World \\
\hline Total & -531 & $-387,565$ & 358,552 & $-29,545$ \\
Sources of total & & & \\
Change in rents from sales to & - & 62 & -549 \\
$\quad$ Korea & 9,011 & - & 355,630 \\
$\quad$ United States and EEC & $-9,769$ & 5,860 & - \\
$\quad$ Rest of the world & -128 & - & -309 \\
Inefficiency costs & -135 & $-28,846$ & -20 \\
$\quad$ Production & 489 & $-364,641^{\mathrm{a}}$ & 3,800 \\
$\quad$ Consumption & & &
\end{tabular}

- Not applicable.

Note: The U.S. own elasticity for Korean steel is taken to be -10 , and the U.S. cross-elasticity of demand for Korean steel with respect to the price of steel from the rest of the world is taken to be 0.5 . Welfare in postquota equilibrium minus welfare in prequota equilibrium. Negative numbers indicate a decline in welfare.

a. The consumption inefficiency costs of U.S. and EEC consumers on purchases of non-home-produced steel are recorded in the line immediately above and are excluded here to avoid double counting.

Source: As in table 1.

because consumers are not having to divert demand to less preferred types of steel.

\section{The Equivalent Tariff}

The impact of altering the restraint from a quota to an "equivalent tariff" (in the sense defined by Bhagwati 1965) was also estimated retaining the elasticity assumptions underlying tables 1,2 , and 3 . The welfare results are presented in table 10. It follows from the adopted definition of equivalent tariff that the price and trade flow effects are the same as under the quota; thus tables 1 and 2 show these effects. It was found that if the United States and the EEC employed tariff barriers to raise the tariff-inclusive import price in their home market by the same amount as the estimated price increase of the quota, then all three regions in the model lose, while resource misallocation costs for the world are unchanged. Thus, the tariff transforms Korean and rest of the world's welfare gains into net losses.

\section{CONCLUSION}

This article has developed a model through which we may evaluate the effect on a nation of a restraint imposed on its exports by an importing nation. The model was formulated for a three-region model of world trade in a particular product, so that the effects (in terms of price changes and trade flows) on any of the regions may be determined. A methodology was developed for evaluating the resulting welfare changes on any of the regions in the model and on the world. 
Table 10. "Equivalent Tariff” Welfare Costs (thousands of 1984 U.S. dollars per year)

\begin{tabular}{lcrcr}
\hline & Korea & $\begin{array}{c}\text { United States } \\
\text { and EEC }\end{array}$ & $\begin{array}{c}\text { Rest of } \\
\text { the world }\end{array}$ & World \\
\hline Total & $-13,655$ & $-20,409$ & $-2,006$ & $-36,071$ \\
Sources of total & & & & \\
Change in rents from sales to & - & 69 & -548 \\
$\quad$ Korea & $-4,107$ & - & $-4,149$ \\
$\quad$ United States and EEC & $-9,767$ & 6,638 & - \\
$\quad$ Rest of the world & -128 & - & -309 \\
Inefficiency costs & -135 & $-35,372$ & -20 \\
$\quad$ Production & 481 & $8,256^{\mathrm{a}}$ & 3,020 & \\
$\quad$ Consumption & & &
\end{tabular}

- Not applicable.

Note: Welfare in posttariff equilibrium minus welfare in pretariff equilibrium. Negative numbers indicate a decline in welfare.

a. The consumption inefficiency costs of U.S. and EEC consumers on purchases of non-home-produced steel are recorded in the line immediately above and are excluded here to avoid double counting.

Source: As in table 1.

The model has been used to analyze the effects on the Republic of Korea of the restraints (primarily quantitative) imposed on their exports to the United States and the EEC. As expected, it was found that the United States and the EEC suffered significant losses as a result of imposing the restraints. The largest part of these losses was quota rents transferred to Korea and the rest of the world. The resource misallocation costs incurred by the latter two regions were smaller than the quota rents they earned; under most of the reasonable assumptions about the parameters in the model, Korea and the rest of the world gain after the imposition of the quotas. Simulations with a more restrictive quota on Korea combined with a less restrictive quota on the rest of the world showed that the welfare of one restrained region increases (decreases) as the quota on the other exporting region is tightened (loosened). In the case of the steel restraints, an "equivalent" tariff would transform Korea and the rest of the world from net beneficiaries to net losers as a result of a restraint.

Although we were concerned in this article with applying the model to the steel restraints imposed on Korea, other countries or products could be substituted in the model provided the appropriate economic analysis of the values of the parameters was performed. Although definitive qualitative results are often difficult to obtain, the model appears to provide results that are consistent with economic theory, and thus should be useful for obtaining quantitative results on the effects of trade barriers in a variety of contexts.

\section{Appendix: The Mathematical Structure of the Model}

After the United States imposed its quota system, due to the prior existence of the EEC restraint system, essentially no steel beyond the quota level could be 
exported to the United States or the EEC. Thus, it is reasonable to group the United States and the EEC together as one restraining region. Since we are interested in the impact of the quotas on Korea in particular, we separate Korea from the rest of the world in defining the regions of the model. Thus we divide the world into three regions: Korea $(K)$; the United States and the EEC $(U)$; and the rest of the world $(R)$.

It is assumed in the following that each region has demand functions that are differentiated by place of production. This is the Armington (1969) assumption, but the Armington elasticities are not assumed throughout.

\section{Demand Functions}

Each region has a demand function for steel from its own region, as well as for each of the other two regions. If $Q_{i j}$ is defined to be the $i$ th country's demand for the $j$ th country's product, then we take:

$$
Q_{i j}=a_{i j}+\sum_{k} b_{j k}^{i} P_{k} \quad i, j, k \in W=\{K, U, R\}
$$

where $P_{k}$ is the price of the $k$ th region's product, $W$ is the set of the three regions, the $a_{i j} \mathrm{~s}$ are constants, and the $b_{j k}^{i} \mathrm{~s}$ are constants reflecting the slope of the $i$ th region's demand for the $j$ th region's product with respect to a change in the $k$ th region's price. Since there are three regions, we have nine demand functions, where each of the demand functions depends on all of the steel prices. ${ }^{7}$ Clearly there are variables other than price that affect the quantity of steel demanded in a region. We can think of the $a_{i j}$, in equation 1 , as being a function of a vector of parameters that affect the demand for steel, $\left[a_{i j}=f^{i j}(\theta)\right]$. A comparative statics exercise will be conducted, where the vector $\theta$ is held constant at its value in the initial equilibrium. This implies that the $a_{i j}$ s are constants in the comparative statics exercise. ${ }^{8}$

7. If the relevant demand functions or production functions are weakly separable between steel products and other products, then the demand for steel products may be written as a function of the prices of steel products alone and income allocated to steel. Nonsteel prices will affect steel demand only through their impact on the income allocated to steel. By writing the demand functions in the manner of equation 1 , we are making the weak separability assumption. See Tarr $(1986 \mathrm{~b})$ for a discussion of the implications of weak separability on the elasticities of demand. With this assumption the model is in the spirit of "quasi" general equilibrium models; see Corado and de Melo (1985).

8. More generally we could think of the $Q_{i j}$ as being a function, possibly nonlinear, of the vector of prices and the vector of parameters. That is, $Q_{i j}=F^{i j}(P, \theta)$, where $P$ is the vector of prices of the three regions. The constants $b_{i k}^{i}$ in equation 1 could be thought of as the partial derivatives of the $F^{i i}$ evaluated at equilibrium. That is,

$$
b_{j k}^{i}=\frac{\delta F^{i i}(P, \theta)}{\delta P_{K}},
$$

where the partial derivatives are evaluated at the values of $P$ and $\theta$ in the initial equilibrium. The set of demand equations 1 would then represent a linear approximation to the demand equations $F^{i j}$ in the neighborhood of the initial equilibrium. For changes in prices or quantities in the neighborhood of equilibrium, we could use equations 1 to approximate the changes in $F^{i j}$.

The demand elasticities that we employ are based on the work of Grossman (1982) and Armington (1969). Since both of those authors employed specifications that resulted in constant own and cross-elasticities of demand, the slopes employed in equations 1 are linear approximations to the constant elasticities and are accurate in a neighborhood of equilibrium. 


\section{Supply Functions}

A supply function is specified for each region:

$$
S_{i}=\alpha_{i}+\beta_{i} P_{i} \quad i \in W
$$

where $S_{i}$ is the quantity supplied in the $i$ th country, and the $\alpha_{i}$ and $\beta_{i}$ are constants with interpretations analogous to the $a_{i j}$ and $b_{j k}^{i}$ of the demand functions. ${ }^{9}$

\section{Equilibrium Conditions}

For equilibrium to prevail it is necessary that:

$$
S_{j}(p)=Q_{i}(p)=\sum_{i} Q_{i j}(p) \quad \quad i, j \in W
$$

where $Q_{j}(p)$ is the aggregate demand across regions for the $j$ th region's product, and $p$ is the vector of prices. If we define the $i$ th region's excess supply as:

$$
X_{i}(p)=S_{i}(p)-Q_{i i}(p) \quad i \in W
$$

then equation 3 is equivalent to:

$$
X_{j}(p)=\sum_{i \neq j} Q_{i j}(p) \quad i, j \in W .
$$

Suppose we work with the system of equations defined by equation 3 . Then equilibrium exists at:

$$
\alpha_{j}+\beta_{j} P_{j}=a_{j}+\sum_{k} \hat{b}_{j k} P_{k} \quad j, k \in \mathrm{W}
$$

where we define the variables $a_{j}=\sum_{i} a_{i j}$ and $\hat{b}_{i k}=\sum_{i} b_{j k}$ for $i, j, k \in W$. Converting to matrix notation, equilibrium is at:

$$
p=[B-\beta]^{-1}[\alpha-a]
$$

where $\alpha$ and $a$ are vectors of the $\alpha_{i}$ and $a_{i}, B$ is a three-by-three matrix of the $\hat{b}_{j k}$, that is, $B=\left[\hat{b}_{j k}\right]$, and $\beta$ is a diagonal matrix with the $\beta_{i}$ on the diagonal. With the equilibrium price vector, the quantities going to each region are determined from equation 1.

Equations 1 characterize the demand functions of the regions when there are no restraints. If quantitative restraints are imposed, however, the equations would have to be altered. That is, the quantity of steel entering the region $U$ from $K$ and $R$ is fixed by the quotas, yielding $Q_{U K}=Q_{U K}^{*}$ and $Q_{U R}=Q_{U R}^{*}$, where the asterisk denotes the fixed quantity set by virtue of the cuota. This reduces the

9. Each supplier is assumed to be indifferent as to the place of sale and sells to the highest bidder. Thus only one price is specified in the supply functions.

In our model we aggregate over all steel products. In fact, there are many steel products, and producers have a certain amount of ability to substitute production of one for another. The supply function would more accurately be characterized in disaggregated form as a function of the prices of all the separate products the producers are able to produce. When a quota is imposed, producers may substitute production of one product for another as profit conditions and constraints indicate. Such diversion and upgrading possibilities should imply that constrained producers lose less than will be implied by the aggregate approach taken here (see, for example, Falvey 1979). 
number of unknown quantity variables that have to be determined from nine to seven.

Conversely, the existence of the quota in the region $U$ implies, for binding levels of the quota, that there is a wedge between the price of Korean steel in $U$ and the price of Korean steel in $K$ and $R$. Similarly, there is a wedge between the price of steel from $R$ in $U$ and the price of steel from $R$ in $K$ and $R$. This implies that while there were only three prices in the prequota system, there are five prices to determine after the quota is imposed: $P_{K}$, the price of Korean steel in Korea and $R ; P_{U}$, the price of steel from $U ; P_{R}$, the price of steel from the rest of the world in $R$ and $K ; P_{K U}$, the price of Korean steel in $U$; and $P_{R U}$, the price of steel from $R$ in $U$. In what follows, define the price vector $P^{t}=\left(P_{K}, P_{U}, P_{R}, P_{K U}, P_{R U}\right)$, where the superscript $t$ denotes transpose so that $P$ is a column vector.

Assume that in the postquota equilibrium the quotas are binding and let $\hat{Q}_{K}(P)$ equal the demand for Korean steel from $R$ and $K$ after the quota. Then, since there is no price wedge in $K$ or $R$ we have:

$$
\hat{Q}_{K}(P)=Q_{K K}(P)+Q_{R K}(P)
$$

where the demand functions on the right-hand side of equation 8 come from equation 1 . Similarly, for the region $R$ we have:

$$
\hat{Q}_{R}(P)=Q_{K R}(P)+Q_{R R}(P)
$$

where again the right-hand-side functions come from equation 1.

With binding quotas, the Korean price in $U$ exceeds the Korean price elsewhere, that is, $P_{K U}>P_{K}$, where $P_{K}$ is taken to be the price of Korean steel outside of $U$. Similarly, $P_{R U}>P_{R}$. Korean suppliers will therefore fill their quota allotment in $U$ before selling any steel elsewhere. This implies that the steel supply function of $K$ to regions outside of $U$ is equal to the original supply function less the quota allotment to $U$. Thus, for equilibrium to prevail in the market for Korean steel outside of $U$, we must have the quantity of Korean steel demanded outside of $U$ equal to the quantity of Korean steel supplied outside of $U$ :

$$
\hat{Q}_{K}(P)=Q_{K K}(P)+Q_{R K}(P)=\alpha_{K}-Q_{U K}^{*}+\beta_{K} P_{K} .
$$

An alternative way of arriving at equation 10 is to consider the demand for Korean steel from all sources. This would be: $\hat{Q}_{K}(P)+Q_{U K}^{*}$. This total demand would have to be equal to the total supply for equilibrium to prevail. Since, at the margin, Korean suppliers will receive the price $P_{K}$ that prevails outside of $U$, for equilibrium we have:

$$
\hat{Q}_{K}(P)+Q_{U K}^{*}=\alpha_{K}+\beta_{K} P_{K} .
$$

Equations 10 and 11 are obviously equivalent.

An entirely analogous argument for the region $R$ yields a second equilibrium condition:

$$
\hat{Q}_{R}(P)=Q_{K R}(P)+Q_{R R}(P)=\alpha_{R}-Q_{U R}^{*}+\beta_{R} P_{R}
$$


Define $b_{j k}=\sum_{i \neq U} b_{j k}^{i}$. Then substituting the relevant demand functions from equation 1 into equation 10, and utilizing the definition of $b_{j k}$ yields the version of the equilibrium condition with which we will work:

$$
\left(b_{K K}-\beta_{K}\right) P_{K}+b_{K U} P_{U}+b_{K R} P_{R}=\alpha_{K}-Q_{U K}^{*}-a_{K K}-a_{R K} .
$$

Arguing analogously again for the region $R$ yields the equilibrium condition:

$$
b_{R K} P_{K}+b_{R U} P_{U}+\left(b_{R R}-\beta_{R}\right)=\alpha_{R}-Q_{U R}^{*}-a_{K R}-a_{R R} .
$$

Now consider the supply and demand for steel from producers in the region $U$. If there is to be equilibrium, it is necessary that quantity demanded equals quantity supplied in this market:

$$
Q_{U}(P)=Q_{K U}(P)+Q_{U U}(P)+Q_{R U}(P)=\alpha_{U}+\beta_{U} P_{U}
$$

Since the regions $K$ and $R$ are not restraining imports and have no wedges between their home prices and world prices, we may substitute for $Q_{K U}(P)$ and $Q_{R U}(P)$ from equation 1 into equation 15 . With respect to the region $U$, however, we must substitute the prices actually faced by consumers in $U$ into their demand function. Since they face higher prices than exist elsewhere in the world, we have:

$$
Q_{U U}(P)=a_{U U}+\sum_{j \in W} b_{U_{j}}^{U} P_{j U},
$$

where $P_{j U}$ is the price of the $j$ th region's product in $U$ and $P_{U U}=P_{U}$. Also substituting equation 16 into equation 15 yields the equilibrium condition:

(17) $b_{U K} P_{K}+\left(\hat{b}_{U U}-\beta_{U}\right) P_{U}+b_{U R} P_{R}+b_{U K}^{U} P_{K U}+b_{U R}^{U} P_{R U}=\alpha_{U}-a_{U}$ where, as in equation 6 , we define $\hat{b}_{U U}=\sum_{j \in W} b_{U U}^{i}$.

We now have three equations, from the three equilibrium conditions, but five unknowns in the price vector. The additional two equations required are the equations that clear the market for steel from $K$ and $R$ in $U$. When the region $U$ imposes a quota on steel from $K$ or $R$, the prices must adjust to clear the market at the fixed quantity. Thus, we focus on the region $U$ 's demand functions for steel from $K$ and $R$, respectively. We have:

$$
\sum_{j \in W} b_{K j}^{U} P_{j U}=Q_{U K}^{*}-a_{U K}
$$
and

Combining the five equilibrium conditions, we have:

$$
\begin{gathered}
\left(b_{K K}-\beta_{K}\right) P_{K}+b_{K U} P_{U}+b_{K R} P_{R}=\alpha_{K}-Q_{U K}^{*}-a_{K K}-a_{R K} \\
b_{U K} P_{K}+\left(\hat{b}_{U U}-\beta_{U}\right) P_{U}+b_{U R} P_{R}+b_{U K}^{U} P_{K U}+b_{U R}^{U} P_{R U}=\alpha_{U}-a_{U} \\
b_{R K} P_{K}+b_{R U} P_{U}+\left(b_{R R}-\beta_{R}\right)=\alpha_{R}-Q_{U R}^{*}-a_{K R}-a_{R R} \\
b_{K K}^{U} P_{K U}+b_{K U}^{U} P_{U}+b_{K R}^{U} P_{R U}=Q_{U K}^{*}-a_{U K} \\
b_{R K}^{U} P_{K U}+b_{R U}^{U} P_{U}+b_{R R}^{U} P_{R U}=Q_{U R}^{*}-a_{U R} .
\end{gathered}
$$


Define the matrix $A$ as the matrix of coefficients of the price vector in equations 20-24, that is:

$$
A=\left[\begin{array}{lllll}
\left(b_{K K}-\beta_{K}\right), & b_{K U}, & b_{K R}, & 0, & 0 \\
b_{U K}, & \left(\hat{b}_{U U}-\beta_{U}\right), & b_{U R}, & b_{U K}^{U}, & b_{U R}^{U} \\
b_{R K}, & b_{R U}, & \left(b_{R R}-\beta_{R}\right), & 0, & 0 \\
0, & b_{K U}^{U}, & 0, & b_{K K}^{U}, b_{K R}^{U} \\
0, & b_{R U}^{U}, & 0, & b_{R K}^{U}, b_{R R}^{U}
\end{array}\right]
$$

Define the vector $c$ as the vector of constants on the right-hand side of equations 20-24. We may rewrite $20-24$ in matrix notation as:

$$
A P=c \text {. }
$$

The equilibrium price vector can be determined from 25 by inverting:

$$
P=A^{-1} c \text {. }
$$

Once we have the predicted postquota equilibrium prices and quantities, we can calculate welfare effects of the quotas on all three regions. The methodology for performing the welfare calculation, which is an extension of the Burns (1973) methodology, is developed in Tarr (1986a).

\section{REFERENCES}

Armington, Paul. 1969. "A Theory of Demand for Products Distinguished by Place of Production." IMF Staff Papers 16: 159-78.

Bhagwati, Jagdish. 1965. "On the Equivalence of Tariffs and Quotas." In Trade, Growth, and the Balance of Payments, ed. R. Caves and others. Chicago: Rand McNally.

Burns, Michael. 1973. "A Note on the Concept and Measure of Consumers' Surplus." American Economic Review 63: 335-44.

Corado, C., and J. de Melo. 1985. "A Simulation Model to Estimate the Effects of Portugal's Entry into the Common Market." Economia 9: 403-30.

Corden, W. M. 1957. "The Calculation of the Cost of Protection." Economic Record 33: 29-51.

Falvey, Rodney. 1979. "The Composition of Trade within Import Restricted Product Categories." Journal of Political Economy 87: 1105-114.

Grossman, Gene. 1982. "Import Competition from Developed and Developing Countries." Review of Economics and Statistics 64: 271-81.

Harberger, Arnold. 1971. "Three Basic Postulates for Applied Welfare Economics: An Interpretive Essay." Journal of Economic Literature 9: 785-97.

Magee, Stephen. 1972. "The Welfare Effects of Restrictions on U.S. Trade." Brookings Paper on Economic Activity 3: 645-701.

Tarr, David. 1986a. "Effects of Restraining a Nation's Exports: The Case of Restraints on Korean Steel Exports by the United States and the European Community." Washington, D.C.: Development Research Department, World Bank. Processed. . 1986b. "A Note on Choosing among Competing Sets of Estimates of Cross- 
418 THE WORLD BANK ECONOMIC REVIEW, VOL. 1, NO. 3

Elasticities of Demand." Washington, D.C.: Development Research Department, World Bank. Processed. (Available upon request from the author.)

Forthcoming. "The Steel Crisis in the United States and the European Community: Causes and Consequences." In Europe-United States Trade Relations, ed. Robert Baldwin and others. Chicago: University of Chicago Press.

Tarr, David, and Morris Morkre. 1984. Aggregate Costs to the United States of Tariffs and Quotas on Imports. Washington, D.C.: U.S. Federal Trade Commission. 